\title{
ARTIGO
}

DOI: https://doi.org/10.22481/praxis.v15i31.4678

\section{COMO FORMAR PROFESSORES? CONCEPÇÕES DE PÓS-GRADUANDOS EM EDUCAÇÃO}

\author{
HOW TO TEACH TEACHERS? EDUCATIONAL POST-GRADUANTS CONCEPTIONS
}

\author{
CÓMO FORMAR PROFESORES? CONCEPCIONES DE POST-GRADUANDOS EN \\ EDUCACIÓN
}

\author{
Monica Lopes Folena Araújo \\ Universidade Federal Rural de Pernambuco - Brasil \\ Maria Inêz Oliveira Araújo \\ Universidade Federal de Sergipe - Brasil
}

\begin{abstract}
Resumo: A presente pesquisa teve por objetivo geral compreender as concepções de pós-graduandos em educação sobre como formar professores. Nesse sentido, especificamente objetivamos: promover a Sequência Didática Interativa (SDI) como instrumento de coleta de dados e também metodologia formativa e comparar concepções sobre como formar professores antes e após a vivência de uma disciplina sobre formação de professores. Os resultados indicaram que a pesquisa-ação, a necessidade de se conhecer metodologias diversas, de refletir sobre a docência, a unidade teoria-prática, a criticidade e a humanização são alguns dos aspectos relevantes a serem considerados no processo formativo.
\end{abstract}

Palavras-chave: Concepções. Formação de professores. Pós-Graduação em Educação.

\begin{abstract}
The present research had as general objective to understand the conceptions of postgraduate students in education on how to train teachers. In this sense, we had as specific objectives: to promote the Interactive Didactic Sequence (SDI) as an instrument of data collection and also formative methodology and to compare conceptions about how to train teachers before and after the experience of a discipline about teacher training. The results indicated that action research, the need to know different methodologies, to reflect on teaching, the unit theory-practice, criticality and humanization are some of the relevant aspects to be considered in the training process.
\end{abstract}

Keywords: Conceptions. Post-Graduation in Education. Teacher training.

Resumen: La presente investigación tuvo por objetivo general comprender las concepciones de postgraduados en educación sobre cómo formar profesores. En este sentido, específicamente objetivamos: promover la Secuencia Didáctica Interactiva (SDI) como instrumento de recolección de datos y también metodología formativa y comparar concepciones sobre cómo formar profesores antes y después de la vivencia de una disciplina sobre formación de profesores. Los resultados indicaron que la investigación-acción, la necesidad de conocer metodologías diversas, de reflexionar sobre la 
docencia, la unidad teoría-práctica, la criticidad y la humanización son algunos de los aspectos relevantes a ser considerados en el proceso formativo.

Palabras clave: Concepciones. Formación de profesores. Posgrado en Educación.

\section{A formação de professores como ponto de partida}

Uma das linhas de pesquisa em programas de pós-graduação em educação e em ensino e de Grupos de Trabalhos (GT) em eventos acadêmicos que mais ganha adeptos nos últimos anos é formação de professores. Isso porque formar professores, diante das exigências sociais da atualidade e para o futuro, torna-se tarefa árdua, pois se faz mister sucessivas mudanças em busca do seu aprimoramento, no que diz respeito a sua função técnica e social, e consequente melhor formação de profissionais para atuarem na Educação Básica de uma sociedade desigual.

$\mathrm{Na}$ atualidade, as instituições formadoras enfrentam o desafio de modificar as matrizes curriculares dos cursos de licenciatura atendendo as Diretrizes Curriculares Nacionais para a Formação Inicial e Continuada em Nível Superior de Profissionais do Magistério para a Educação Básica (DCN), definidas pela Resolução $n^{\circ} 2$, de $1^{\circ}$ de julho de 2015 . Na referida Resolução compreende-se a docência como

[...] ação educativa e como processo pedagógico intencional e metódico, envolvendo conhecimentos específicos, interdisciplinares e pedagógicos, conceitos, princípios e objetivos da formação que se desenvolvem na construção e apropriação dos valores éticos, linguísticos, estéticos e políticos do conhecimento inerentes à sólida formação científica e cultural do ensinar/aprender, à socialização e construção de conhecimentos e sua inovação, em diálogo constante entre diferentes visões de mundo.

Frente a tal compreensão, podemos inferir a responsabilidade atribuída às instituições formadoras de professores e também aos professores formadores de professores. Para Garcia (1999), as instituições formadoras têm essencialmente três funções: a de formação dos futuros

professores “[...] de modo a assegurar uma preparação consoante com as funções profissionais que o professor deverá desempenhar” (p. 77), a de certificação para o exercício da docência e a de agente de mudança do sistema educativo.

Quanto às metas e finalidades da formação de professores, o supracitado autor nos ajuda a refletir sobre que conhecimentos são necessários à formação inicial. E, nesse contexto destaca: o conhecimento psicopedagógico, o conhecimento do conteúdo, o conhecimento didático do conteúdo e o conhecimento do contexto. O conhecimento psicopedagógico refere- 
se ao "relacionado com o ensino, a aprendizagem, com os alunos [...]" (GARCIA, 1999, p. 86); o conhecimento do conteúdo refere-se a saber sobre aquilo que se vai ensinar e este divide-se em conhecimento substantivo, ou seja, "os conceitos específicos, definições, convenções e procedimentos" (Idem, p. 87) e o conhecimento sintático, que completa o substantivo "[...] e tem a ver com o domínio que o professor tem dos paradigmas de investigação em cada disciplina [...] tendências, perspectivas [...]” (Idem, p. 87); conhecimento didático do conteúdo, ou seja, o como ensinar; e o conhecimento do contexto, que, para o autor, inclui o respeito ao local onde se ensina, assim como a quem se ensina.

Tardif (2008) entende que a formação para o ensino não pode limitar-se a conhecimentos e competências; deve envolver também valores, compromissos normativos e convicções éticas, já que o professor trabalha "[...] com, sobre e para seres humanos em desenvolvimento e aprendizado. Trata-se, no sentido forte, de um trabalho de interações humanas" (p. 41). Portanto, faz-se necessário que os cursos de formação de professores busquem inserir nos componentes curriculares o contexto em que seus estudantes, futuros professores, estão inseridos, para que eles possam compreender e assumir seu papel social, afinal, só instrumentalizar o professor não contribui para a formação de pessoas com engajamento social.

De acordo com Nóvoa (1995), na formação de professores, têm-se ignorado o desenvolvimento pessoal - confunde-se "formar" com "formar-se". Isso significa, para Araújo (2015), que está voltada para a instrumentalização técnica em que não se priorizam análises críticas, por consequência não contribui para uma sociedade mais justa, humana e socioambientalmente sustentável, embora haja esforços de renovação.

Para a autora (2015, p. 102):

A formação do professor é, desse modo, um campo profissional movido por muitas necessidades formativas no sentido de preparar pessoas com conhecimentos e atividades profissionais específicas. Todavia, em nossa sociedade, testemunhamos todos os dias a situação de pouco poder e prestígio profissional dos professores da educação básica, o que provoca tensões na sua formação inicial. Não raro, encontramos licenciandos que confidenciam sua antipatia pela docência e o desejo de não exercê-la.

Evidencia-se, frente ao exposto, a importância dos cursos de licenciatura na formação de professores. Entretanto, estudos de Gatti revelam que os cursos de licenciatura mostram-se estanques entre si e, também, "segregam a formação na área específica dos conhecimentos pedagógicos dedicando parte exígua de seu currículo às práticas profissionais docentes, às questões da escola, da didática e da aprendizagem escolar” (GATTI, 2013-2014, p. 39). 
Outro estudo da autora indica que a formação de professores é feita de forma fragmentada entre as áreas disciplinares e também entre os níveis de ensino, não havendo uma faculdade ou instituto responsável pela formação de professores, "com uma base comum formativa, como observado em outros países, onde há centros de formação de professores englobando todas as especialidades, com estudos, pesquisas e extensão relativos à atividade didática e às reflexões e teorias a ela associadas" (GATTI, 2010, p. 1358).

Formosinho (2009) defende a formação de professores como aprendizagem profissional da ação docente, ou seja, do exercício da docência. E, ao desvelar concepções conflitantes de professor, contribui para pensarmos em alguns possíveis estereótipos formativos presentes nas instituições formadoras de professores. $\mathrm{O}$ autor caracteriza cinco tipos diferentes de concepções do que é ser professor: missionária, militante, laboral, burocrática e romântica.

Na concepção missionária o ensino é assumido "como um chamamento e uma missão para cumprir com dedicação e zelo [...] a vocação e o espírito de serviço são consideradas as características essenciais da atividade do professor que motivam a sua entrega à profissão" (FORMOSINHO, 2009, p. 29). Na concepção militante o professor é "um agente social comprometido com a escola e com a comunidade local” (Idem, p. 29). Na concepção laboral o professor "assume-se como um trabalhador qualificado, possuidor de um saber técnico especializado" (Idem, p. 29). Na concepção burocrática o professor é considerado um "cumpridor das normas e dos regulamentos em vigor [...]” (Idem, p. 30). Já na concepção romântica o professor é tido como um artista, assim, o ato de ensinar é uma arte e a criatividade é valorizada.

A concepção do ser professor é fundamental em um curso de formação inicial de professores, pois a partir dela será traçado um perfil de egresso, as disciplinas que comporão a matriz curricular e até mesmo o perfil dos professores formadores. Observando as concepções trazidas por Formosinho (2009) podemos nos perguntar: em qual dessas concepções está o professor crítico, reflexivo, pesquisador e autônomo? Difícil responder. Entretanto, a criticidade, a reflexividade, a pesquisa e a autonomia são indispensáveis à formação de um educador progressista, pois este, como argumenta Freire (2015, p. 81) tem como tarefa:

[...] problematizar aos educandos o conteúdo que os mediatiza, e não o de dissertar sobre ele, de dá-lo, de estendê-lo, de entregá-lo, como se se tratasse de algo já feito, elaborado, acabado, terminado. Neste ato de problematizar os educandos, ele se encontra igualmente problematizado. 
E, para que essa tarefa seja desempenhada é preciso investir na formação inicial e continuada de professores através dos cursos de graduação e pós-graduação, afinal, muitos dos profissionais formados nos cursos de pós-graduação exercerão a docência nas mais diversas áreas do conhecimento.

Diante de tais considerações a respeito da formação de professores e do papel dos cursos de pós-graduação em educação na formação de pesquisadores na área de educação e de profissionais melhor preparados para o exercício da docência, nos perguntamos: quais são as concepções de mestrandos e doutorandos de um programa de pós-graduação em educação sobre como formar professores?

Para darmos conta desse problema de pesquisa de modo coerente, tivemos como objetivo geral: compreender as concepções de pós-graduandos em educação sobre como formar professores. Especificamente objetivamos: promover a Sequência Didática Interativa (SDI) como instrumento de coleta de dados e também metodologia formativa e comparar concepções sobre como formar professores antes e após a vivência de uma disciplina sobre formação de professores, com carga horária de 60 horas/aula. A referida disciplina foi ofertada em 2017.2 e faz parte do Programa de Pós-Graduação em Educação da Universidade Federal de Sergipe, nível mestrado e doutorado.

\section{A Sequência Didática Interativa: caminho para coleta de dados e para a formação}

Oliveira (2013, p. 58) define a SDI como sendo:

[...] uma proposta didático-metodológica que desenvolve uma série de atividades, tendo como ponto de partida a aplicação do Círculo Hermenêutico Dialético para identificação de conceitos/definições, que subsidiam os componentes curriculares (temas), e que são associados de forma interativa com teoria(s) de aprendizagem e/ou propostas pedagógicas e metodológicas, visando a construção de novos conhecimentos e saberes.

O Círculo Hermenêutico-Dialético (CHD) é defendido por Oliveira (2013) como um processo de construção e reconstrução da realidade através da dinâmica de sucessivas modificações (dialética) promovidas pelo diálogo e interação dos atores sociais (dialogicidade e complexidade) para investigar a totalidade de um fato, objeto ou fenômeno (visão sistêmica). Em síntese, "a dialogicidade está relacionada ao processo de interação entre as pessoas, para construção e reconstrução da realidade dentro de uma visão do todo, ou seja, na ótica da complexidade" (OLIVEIRA, 2013, p. 64). 
Capra (2006, p. 40) ajuda-nos a compreender a visão sistêmica ao trazer que:

[...] as propriedades essenciais de um organismo, ou sistema vivo, são propriedades do todo, que nenhuma das partes possui. Elas surgem das interações e das relações entre as partes. Essas propriedades são destruídas quando o sistema é dissecado, física ou teoricamente, em elementos isolados. Embora possamos discernir partes individuais em qualquer sistema, essas partes não são isoladas, e a natureza do todo é sempre diferente da mera soma de suas partes [...].

É nesta perspectiva que a SDI trabalha a realidade - as concepções de uma pessoa são individuais, mas fazem parte de um todo e nesse processo de construção do todo, as concepções individuais podem se modificar a partir do conhecimento de outras visões de mundo, outros referenciais teóricos, outros contextos formativos. Assim, a SDI caracteriza-se como um método para coleta de dados em uma pesquisa, mas também se constitui um processo formativo para todos os envolvidos no processo. Ressaltamos, nesse processo formativo, a dialética "como estudo da realidade em seu movimento, argumentação, complexidade e análise das "contradições"” (OLIVEIRA, 2013, p. 67).

Apresentamos o CHD, primeira etapa da SDI, na Figura 1.

Figura 1 - Círculo Hermenêutico-Dialético (CHD)

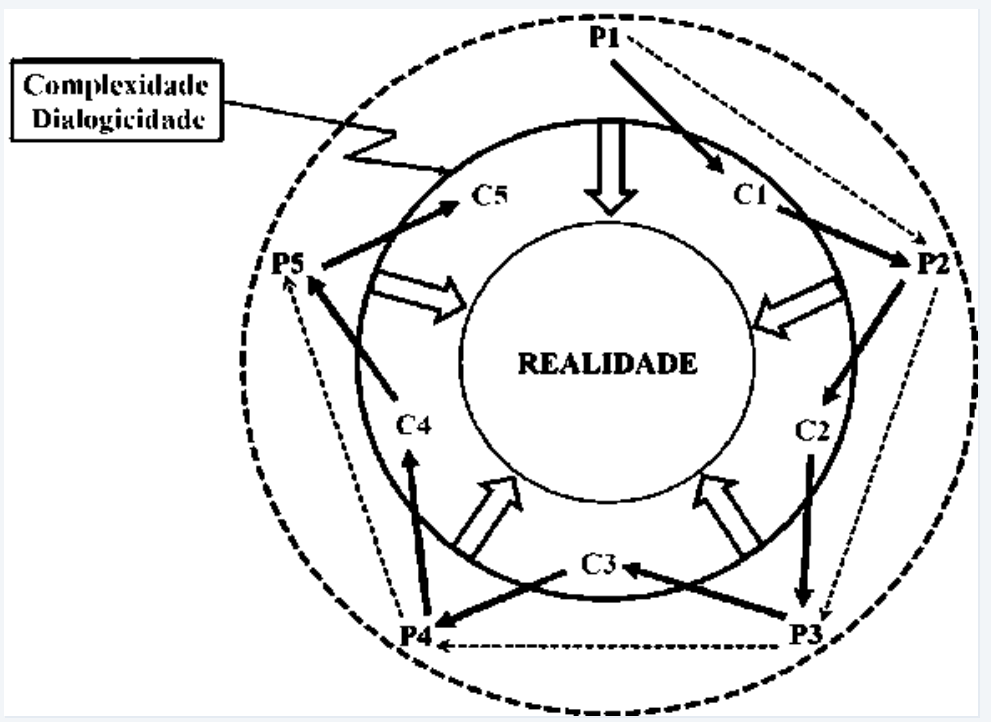

Fonte: Modificado de Oliveira (2013, p. 63)

Tomando como referência Oliveira (2013) destacamos que o círculo pontilhado representa o grupo de mestrandos e doutorandos participantes, representados pela letra "P". As setas pontilhadas indicam a ordem de organização das respostas. O segundo círculo representa as construções e reconstruções da realidade que vão sendo realizadas a partir da 
interação entre os atores e a produção das sínteses. O círculo do centro representa a realidade construída coletivamente e validada no fechamento do CHD. A seguir detalhamos a aplicação da SDI, seguindo os passos orientados por Oliveira (2013):

1. Elaboramos a pergunta que está relacionada ao objetivo desse trabalho e da disciplina ofertada no programa que serviu como campo de estudo, qual seja: Como formar professores?

2. No primeiro dia de aula, entregamos um papel para cada pós-graduando e solicitamos que respondessem a questão; dividimos a turma, constituída por treze pósgraduandos em quatro grupos, sendo: três grupos com três participantes e um grupo com quatro.

3. Uma vez formados os pequenos grupos, pedimos que os mesmos dialogassem sobre as respostas individuais e construíssem uma síntese. Nesta fase, orientamos que as sínteses buscassem contemplar as respostas individuais dos participantes.

4. Logo após, requisitamos que cada equipe escolhesse um representante para constituir um grupo com os quatro líderes que tinham a função de construir uma síntese das respostas de todos os grupos. Essa síntese foi lida para toda a turma e os participantes tiveram então a oportunidade de modificar as respostas, caso as mesmas não expressassem o que foi consenso nos grupos. Foram utilizadas três horas/aula para as atividades descritas nos itens 2, 3 e 4 .

5. Nas aulas posteriores à primeira, totalizando 52 horas/aula, foram trabalhados conceitos teóricos que envolvem a formação de professores, tais como: docência, profissionalização, autonomia, pesquisa, saberes docentes, políticas de formação de professores e interdisciplinaridade. Tais conceitos foram abordados através da leitura e discussão de textos disponibilizados com antecedência, aulas expositivas dialogadas, leitura de imagens e discussão sobre vídeos, além da participação de convidados na disciplina. Um deles, Bernard Charlot, é autor de referência sobre saberes docentes e o outro, professor de instituto federal, vivenciou formação na Finlândia e compartilhou como é a formação de professores no país, bem como particularidades em relação ao exercício da docência.

6. Na última aula da disciplina, reaplicamos a SDI com a mesma pergunta. Desse modo, repetimos o que explicamos nas etapas 2, 3 e 4, para as quais foram necessárias três horas/aula. Na etapa 4 tivemos o cuidado de manter nos grupos os mesmos participantes da SDI inicial.

Em relação à SDI vale salientar a importância da sondagem inicial para a construção de um conceito ou de uma resposta "[...] que é resultante de um conhecimento que foi 
construído ao longo de suas experiências, cujas ideias foram assimiladas ao longo de sua existência/experiência sobre a temática que se pretende trabalhar no contexto da sala de aula [...]" (OLIVEIRA, 2013, p. 61).

Nesse contexto, destacamos que os atores sociais da pesquisa foram: um mestrando e dois doutorandos do Programa de Pós-Graduação em Ensino das Ciências da Universidade Federal Rural de Pernambuco; seis doutorandas do programa no qual ocorreu a disciplina; dois mestrandos do Programa de Pós- Graduação em Ensino de Ciências e Matemática na instituição na qual ocorreu a disciplina; uma mestranda do Programa de Pós-Graduação em Letras da instituição estudada; e um aluno especial, que aspira cursar o doutorado em Educação no Programa de Pós-Graduação em Educação da referida instituição. Os participantes da pesquisa foram nomeados pela letra "P" seguida de um número, desse modo, as identificações variam de P1 a P13.

Em relação à formação e atuação dos atores sociais: cinco são bolsistas e dedicam-se integralmente ao doutorado, três são bolsistas de mestrado e dedicam-se integralmente aos estudos, uma é doutoranda e atua com a Educação Infantil, uma é doutoranda e professora de uma universidade pública situada no Pará, um é mestrando e atua como professor nos anos finais da Educação Básica, um é doutorando e atua como engenheiro agrônomo em universidade pública situada em Pernambuco e um é aluno especial e atua como professor em instituto federal situado em Sergipe.

Essa caracterização dos atores sociais permite-nos perceber a riqueza do grupo participante da disciplina e o quanto o tema formação de professores atrai pós-graduandos envolvidos em Programas de Pós-Graduação em Educação e em Ensino de Ciências.

\section{Resultados e discussão}

Apresentamos no Quadro 1 as respostas obtidas na SDI inicial e final em relação à pergunta “Como formar professores?". No mesmo explicitamos as respostas individuais dos participantes do Grupo 1e a síntese construída no mesmo.

Quadro 1- SDI inicial e final em relação à pergunta "Como formar professores?"

\begin{tabular}{|c|c|c|}
\hline \multirow[t]{2}{*}{ Grupo 1} & $\begin{array}{l}\text { Respostas individuais e síntese na SDI } \\
\text { inicial }\end{array}$ & $\begin{array}{l}\text { Respostas individuais e síntese na SDI } \\
\text { final }\end{array}$ \\
\hline & $\begin{array}{l}\text { "A formação docente é um processo } \\
\text { contínuo que pode se iniciar na inserção } \\
\text { acadêmica e percorrer toda a vida } \\
\text { profissional. Para tanto, faz-se } \\
\text { necessária a imersão dos sujeitos não } \\
\text { somente em relação aos estudos }\end{array}$ & $\begin{array}{l}\text { "É necessário levar em consideração o } \\
\text { professor como sujeito atuante, como ser } \\
\text { pensante. A formação deve buscar explorar } \\
\text { esse contexto de forma a direcionar os } \\
\text { profissionais em questão a vislumbrar os } \\
\text { processos inerentes à educação como }\end{array}$ \\
\hline
\end{tabular}




\begin{tabular}{|c|c|}
\hline $\begin{array}{l}\text { existentes, como também no que diz } \\
\text { respeito a vivências nos espaços } \\
\text { educativos" (P1). }\end{array}$ & $\begin{array}{l}\text { flexíveis e inovadores perante a dinâmica } \\
\text { planetária" (P1). }\end{array}$ \\
\hline $\begin{array}{l}\text { "Criando oportunidades de acesso aos } \\
\text { processos de ensino/aprendizagem } \\
\text { contextualizados com a } \\
\text { expectativas/demandas/necessidades da } \\
\text { sociedade onde se inserem os futuros } \\
\text { professores/alunos" (P2). }\end{array}$ & $\begin{array}{l}\text { "Proporcionando de } \\
\text { formação inicial e continuada nas quais o } \\
\text { contexto das expectativas/demandas da } \\
\text { sociedade, o papel do conhecimento e da } \\
\text { mobilização de saberes sejam valorizados, } \\
\text { no sentido de formar sua autonomia" (P2). }\end{array}$ \\
\hline $\begin{array}{l}\text { "A formação não deve se restringir à } \\
\text { universidade, para se formar bons } \\
\text { professores é preciso que este } \\
\text { profissional esteja ligado ao seu futuro } \\
\text { campo de atuação, a escola, ou seja, } \\
\text { formar professores interligados com a } \\
\text { vida" (P3). }\end{array}$ & $\begin{array}{l}\text { "Aqui não cabem apenas as instituições de } \\
\text { ensino, mas sim de toda uma sociedade. É } \\
\text { preciso uma mobilização de todos para que } \\
\text { cada formação não trabalhe apenas os } \\
\text { conhecimentos técnicos e científicos do } \\
\text { ensinar, mas percebam que estamos } \\
\text { formando professores para a sociedade. } \\
\text { Assim, o formar deve transcender a } \\
\text { academia" (P3). }\end{array}$ \\
\hline $\begin{array}{l}\text { "Criando oportunidades de acesso aos } \\
\text { processos de ensino/aprendizagem, } \\
\text { contextualizadas com as as a } \\
\text { expectativas/demandas/necessidades da } \\
\text { sociedade, na qual se inserem os futuros } \\
\text { professores/educandos. Sendo assim, a } \\
\text { formação docente é um processo } \\
\text { contínuo e permanente, que pode se } \\
\text { iniciar na inserção acadêmica e percorrer } \\
\text { toda a vida profissional" (Síntese - P1, } \\
\text { P2 e P3). }\end{array}$ & $\begin{array}{l}\text { "Proporcionando oportunidades de } \\
\text { formação inicial e continuada as quais } \\
\text { favoreçam o contexto das demandas da } \\
\text { sociedade, o papel do conhecimento e da } \\
\text { mobilização dos saberes. Ou seja, é preciso } \\
\text { atuação de todos para que esta formação } \\
\text { não seja apenas acadêmica, mas também } \\
\text { envolva o social. Dessa maneira, a } \\
\text { formação deve buscar explorar tais } \\
\text { contextos de forma a direcionar os } \\
\text { profissionais em questão a vislumbrar os } \\
\text { processos inerentes à educação como } \\
\text { flexíveis e inovadores perante a dinâmica } \\
\text { planetária" (Síntese-P1, P2 e P3). }\end{array}$ \\
\hline
\end{tabular}

Fonte: As autoras

O participante P1, na SDI inicial, destacou que, por compreender a formação de professores como processo, a mesma deve dar-se nas instituições formadoras, mas também nos espaços educativos de exercício da docência, ou seja, nas escolas. Neste sentido, aproxima-se da concepção de formação de professores de Formosinho (2009), pois esta, segundo o autor, é a aprendizagem da ação docente em si. Já na SDI final, o mesmo defende que a formação do professor precisa inserir a criticidade, pois estamos diante de uma dinâmica planetária que exige a formação de seres humanos cada vez mais atuantes.

Canário (2000) defende que a aprendizagem profissional deva ocorrer nos locais onde o futuro trabalho se realiza, no caso dos professores, nas escolas. Desse modo, o professor pode ser visto como "[...] um analista simbólico a quem compete equacionar e 'construir' problemas, no terreno da prática, marcada pela incerteza e a complexidade, e não a dar respostas previamente aprendidas para situações inteiramente previsíveis” (Idem, p. 14, grifo do original). 
A parceria universidade-escola na formação de professores tem sido buscada via programas como o Programa Institucional de Bolsas de Iniciação à Docência (PIBID), que tem como alguns dos objetivos, segundo o Artigo $4^{\circ}$, da Portaria ${ }^{\circ} 46$ da Coordenação de Aperfeiçoamento de Pessoal de Nível Superior (CAPES), de 11 de abril de 2016:

\footnotetext{
Art. $4^{\circ}$ São objetivos do PIBID:

I. incentivar a formação de docentes em nível superior para a educação básica; $[\ldots]$

III. elevar a qualidade da formação inicial de professores nos cursos de licenciatura, promovendo a integração entre educação superior e educação básica;

IV. inserir os licenciandos no cotidiano de escolas da rede pública de educação, proporcionando-lhes oportunidades de criação e participação em experiências metodológicas, tecnológicas e práticas docentes de caráter inovador e interdisciplinar que busquem a superação de problemas identificados no processo de ensino e aprendizagem;

$[\ldots]$

VII. contribuir para que os estudantes de licenciatura se insiram na cultura escolar do magistério, por meio da apropriação e da reflexão sobre instrumentos, saberes e peculiaridades do trabalho docente.
}

Entretanto, a parceria universidade-escola na formação inicial de professores não pode estar condicionada ao PIBID ou a qualquer outro programa. É preciso que as instituições formadoras, em diálogo com as escolas, encontrem formas de viabilizar a inserção dos licenciandos no ambiente escolar, de modo que os mesmos tenham a oportunidade de vivenciar a escola e nela construir conhecimentos que sejam base para o futuro exercício profissional. Notadamente, os estágios supervisionados obrigatórios, com carga horária de quatrocentas horas/aula representam possibilidade de inserção nas escolas e, nesse contexto, uma pesquisa sobre o assunto, após a implementação das DCN tem relevância social incontestável.

Corroborando com P1, a participante P3 defendeu, na SDI inicial, que a formação do professor não pode dar-se apenas na universidade, mas também no futuro campo de inserção profissional dos professores. Na SDI final, P3 manteve sua concepção sobre como formar professores, mas acrescentou que "[...] o formar deve transcender a academia" e que essa tarefa é de toda a sociedade.

Na SDI inicial, o participante P2 disse que, para formar professores é preciso criar “oportunidades de acesso aos processos de ensino/aprendizagem contextualizados com a expectativas/demandas/necessidades da sociedade onde se inserem os futuros professores/alunos". Destarte, o participante compreende o conhecimento do contexto (GARCIA, 2009), como importante na formação de professores. Na SDI final, P2 atribui que 
tais oportunidades estão na formação inicial e continuada e que nestas, a mobilização de saberes seja valorizada, em uma tentativa de formar professores autônomos. Nóvoa (1991) apregoa que a verdadeira formação é aquela na qual os professores se profissionalizam pela capacidade de desenvolver autonomia e reflexão.

Na síntese do grupo 1 percebemos, na SDI inicial, a compreensão da formação como "processo contínuo e permanente". Na SDI final, essa compreensão é reforçada com a agregação de novos elementos, tais como o reconhecimento da academia como um local formativo, mas não o único, e a valorização das demandas da sociedade ao se pensar a formação de professores. Afinal, os licenciandos serão professores inseridos na sociedade e por eles passarão todos os demais profissionais. Na síntese final cabe destacar a percepção de que os processos que envolvem a educação precisam ser flexíveis e inovadores em face da dinâmica planetária, ou seja, há a valorização do conhecimento psicopedagógico (GARCIA, 2009) na formação de professores.

Um dos aspectos da dinâmica planetária no contexto educacional são as novas exigências colocadas aos professores na atualidade e que, muitas das vezes, os mesmos não foram formados para tal, insere-se a inclusão em diversas perspectivas. A este respeito, Romanowski (2012, p. 197) nos afirma que:

Amplia-se e se aprofunda a precariedade da formação diante dos desafios da educação básica tais como a formação para a inclusão, para diversidade cultural, em que as propostas dos cursos se manifestam tímidas, não vão além da oferta do curso de LIBRAS, nos cursos de licenciatura.

Apresentamos no quadro 2 as respostas obtidas pelos participantes do grupo 2, as individuais e as coletivas, antes e após a SDI.

Quadro 2- SDI inicial e final em relação à pergunta "Como formar professores?"

\begin{tabular}{|c|c|c|}
\hline \multirow[t]{3}{*}{ Grupo 2} & $\begin{array}{l}\text { Respostas individuais e síntese na SDI } \\
\text { inicial }\end{array}$ & $\begin{array}{l}\text { Respostas individuais e síntese na SDI } \\
\text { final }\end{array}$ \\
\hline & $\begin{array}{l}\text { "Acredito que não há uma "receita" para } \\
\text { a formação, pois o processo educacional } \\
\text { e contexto escolar estão em constantes } \\
\text { mudanças" (P4). }\end{array}$ & $\begin{array}{l}\text { "Além da formação inicial, o professor } \\
\text { deve seguir em busca do conhecimento } \\
\text { (formação continuada) para elencar } \\
\text { diversos aspectos relacionados a sua } \\
\text { formação e prática, construindo assim um } \\
\text { sujeito humanizado e reflexivo" (P4). }\end{array}$ \\
\hline & $\begin{array}{l}\text { "Penso que, a formação de professores } \\
\text { deva acontecer a partir de momentos nos } \\
\text { quais estes possam compartilhar } \\
\text { experiências, conhecer novas } \\
\text { metodologias, no qual o objetivo é a } \\
\text { reflexão da sua prática docente" (P5). }\end{array}$ & $\begin{array}{l}\text { "A formação do professor é algo constante, } \\
\text { pois a sua construção é a partir das suas } \\
\text { experiências, na qual se constrói sua } \\
\text { identidade profissional. Acrescento que, } \\
\text { além dessas experiências, a reflexão das } \\
\text { mesmas é necessária para buscar um }\end{array}$ \\
\hline
\end{tabular}




\begin{tabular}{|c|c|}
\hline & $\begin{array}{l}\text { melhor desempenho da sua prática. } \\
\text { Portanto, não existe uma receita para que } \\
\text { ocorra e de como ocorre essa formação, } \\
\text { mas sim de uma mobilização interna de } \\
\text { refletir sobre o seu papel enquanto } \\
\text { profissional" (P5). }\end{array}$ \\
\hline $\begin{array}{l}\text { "A formação de professores deve se } \\
\text { pautar a partir do entendimento do ser } \\
\text { humano de forma integral, } \\
\text { compreendido como um } \\
\text { complexo que requer constantes } \\
\text { reflexões" (P6). }\end{array}$ & $\begin{array}{l}\text { "Formar professores a partir do } \\
\text { entendimento da formação como um } \\
\text { processo complexo e contínuo, de forma } \\
\text { articulada e integrada às diversas dimensões } \\
\text { e concepções envolvidas. Devido à } \\
\text { importância de formar professores, esse } \\
\text { processo deverá perpassar a formação } \\
\text { inicial, continuada, configurando-se num } \\
\text { processo crítico e reflexivo" (P6). }\end{array}$ \\
\hline $\begin{array}{l}\text { "Pensamos que a formação de } \\
\text { professores não possui uma "receita", } \\
\text { pois esta deve se pautar a partir do } \\
\text { entendimento do ser humano de forma } \\
\text { integral e diante disso proporcionar ao } \\
\text { docente momentos de reflexão para sua } \\
\text { prática, uma vez que o processo } \\
\text { educacional e contexto escolar estão em } \\
\text { constantes mudanças" (Síntese - P4, P5 } \\
\text { e P6) }\end{array}$ & $\begin{array}{l}\text { "Não existe uma receita para que ocorra e } \\
\text { de como ocorre a formação docente, mas } \\
\text { sim de uma mobilização interna (formação } \\
\text { continuada), para se refletir sobre o seu } \\
\text { papel enquanto profissional e sua prática. } \\
\text { Percebe-se que, esse processo é complexo e } \\
\text { contínuo de forma articulada e integrada a } \\
\text { diversas dimensões, concepções que } \\
\text { formam um sujeito crítico e reflexivo da } \\
\text { sua prática" (Síntese - P4, P5 e P6). }\end{array}$ \\
\hline
\end{tabular}

Fonte: As autoras

Os participantes do grupo 2, no primeiro momento da SDI, destacaram que para se formar professores não há uma "receita", como atestou P4, mas citaram a importância de se compartilhar experiências e de conhecer novas metodologias (P5), pautando-se no "[...] ]entendimento do ser humano de forma integral" (P6). Além disso, destacaram que a formação deve "[...] proporcionar ao docente momentos de reflexão para sua prática" (Síntese - P4, P5 e P6).

Para Nóvoa (1998, p. 35), o processo educativo obriga-nos a opções: "as opções que cada um de nós tem de fazer, e que cruzam a nossa maneira de ser com a nossa maneira de ensinar, e que desvendam na nossa maneira de ensinar a nossa maneira de ser”. Assim, o professor é um ser integral que sente, pensa, reflete, toma decisões e age.

Apoiando-nos em Moraes (2004) e em Moraes e Torres (2004) podemos dizer que há um novo paradigma educacional emergente - o eco-sistêmico - que se baseia:

Na ação do aprendiz sobre o mundo, na atuação sobre a sua realidade, no reconhecimento de sua interação com o mundo e no desenvolvimento de diferentes diálogos que o indivíduo estabelece consigo mesmo, com os outros, com a natureza e com o sagrado. (MORAES, 2004, p. 282). 
Estes autores, ao estudarem Maturana e Varela, perceberam que o paradigma ecosistêmico não leva em consideração apenas o que ocorre no cérebro humano, mas sim na totalidade, na integralidade do humano, sendo necessário considerar os sentimentos e as emoções. Nessa perspectiva de integralidade, compartilhar experiências e refletir sobre e na ação docente, constituem-se possibilidades na formação de professores.

Além da formação de professores que considere a integralidade do ser humano, foi destacada a necessidade de se conhecer novas metodologias. Dessa forma, o conhecimento didático do conteúdo (GARCIA, 2009) foi enaltecido na formação de professores. Segundo Santana, Araújo e Santos (2011, p. 74): “[...] tem-se percebido a necessidade de aprimorar e propor novas estratégias pedagógicas e técnicas de ensino em virtude das incertezas e fracassos ocorridos na aprendizagem, bem como superar estagnados métodos de educar".

Nas respostas trazidas pelos participantes na SDI final percebemos que P4, P5 e P6 atentam para a continuidade do processo formativo após a formação inicial, assim como foi apontado pelo grupo 1. Como atestou a participante P6 a formação precisa ser compreendida “[...] como um processo complexo e contínuo", “[...] configurando-se num processo crítico e reflexivo". E a criticidade e reflexão mantiveram-se presentes na síntese do grupo sobre como formar professores, além da necessária "mobilização interna".

Concordamos com Araújo (2015, p. 70) que a "[...] criticidade é condição para a emancipação dos sujeitos, para a formação de sujeitos autores de sua história de vida", assim, a formação de professores precisa estimular os futuros docentes à criticidade. Quando a formação do professor dicotomiza a formação científica e a pedagógica da leitura do mundo, dos fatos e da vida, compromete a prática docente e a postura crítica do futuro professor como profissional e pessoa. A criticidade e a reflexão trazidas pelos participantes possivelmente tiveram a influência de Pedagogia da Autonomia, livro de Paulo Freire trabalhado na disciplina.

Em relação à mobilização interna, percebemos forte influência de textos de Bernard Charlot também estudados na disciplina. Para o autor, o conceito de mobilização é diferente de motivação, pois implica uma relação de o sujeito pôr-se em movimento, ou seja, usar de si próprio como um recurso para realizar uma atividade, uma tarefa. É entrar em uma dinâmica interna (de dentro), é pôr seus próprios recursos em movimento (CHARLOT, 2000). Isso difere de motivar "porque, muitas vezes, esse ato de motivar é o mesmo que enrolar os alunos para que façam alguma coisa que não estão a fim de fazer" (CHARLOT, 2013, p. 159).

No quadro 3, trazemos as concepções individuais dos participantes do grupo 3, bem como as sínteses, na SDI realizada no início e no fim da disciplina. 
Quadro 3- SDI inicial e final em relação à pergunta "Como formar professores?"

\begin{tabular}{|c|c|c|}
\hline \multirow[t]{5}{*}{ Grupo 3} & $\begin{array}{l}\text { Respostas individuais e síntese na SDI } \\
\text { inicial }\end{array}$ & $\begin{array}{l}\text { Respostas individuais e síntese na SDI } \\
\text { final }\end{array}$ \\
\hline & $\begin{array}{l}\text { "Propiciando situações de aprendizagem } \\
\text { que possibilitem pensar a realidade de } \\
\text { forma crítica e refletir sobre a docência } \\
\text { como um campo de luta e de } \\
\text { transformação social" (P7). }\end{array}$ & $\begin{array}{l}\text { "Oportunizando situações de aprendizagem } \\
\text { que busquem promover uma formação que } \\
\text { perpasse o entendimento científico, } \\
\text { necessário ao professor e vislumbre uma } \\
\text { formação reflexiva que tenha como foco o } \\
\text { entendimento do que se configura formar-se } \\
\text { professor, ser professor de modo } \\
\text { concatenado a uma dimensão ética e } \\
\text { política ao longo dessa formação" (P7). }\end{array}$ \\
\hline & $\begin{array}{l}\text { "A formação de professores deve se dar } \\
\text { em diversos ambientes. Formalmente, } \\
\text { temos as instituições superiores de } \\
\text { ensino, que por meio dos seus cursos de } \\
\text { graduação (licenciaturas) e pós- } \\
\text { graduação (especialização, mestrado e } \\
\text { doutorado), voltados para formá-los. } \\
\text { Mas acredito que a formação vem de } \\
\text { todos os espaços, que vai além do } \\
\text { ambiente formal de ensino" (P8). }\end{array}$ & $\begin{array}{l}\text { "A formação é dada em todos os espaços, } \\
\text { mas, para fim de definição, podemos } \\
\text { explanar que, formalmente, a formação de } \\
\text { professores se dá em ambientes } \\
\text { institucionais, por meio dos cursos } \\
\text { (graduação e pós-graduação), como } \\
\text { também vivência "formal" (congressos, } \\
\text { projetos, etc). No âmbito "informal", essa } \\
\text { formação de professores é dada no dia a dia } \\
\text { do professor, por meio do seu processo de } \\
\text { reflexão" (P8). }\end{array}$ \\
\hline & $\begin{array}{l}\text { "A formação pode ser através de cursos } \\
\text { superiores, bem como na vivência em } \\
\text { sala de aula com a prática" (P9). }\end{array}$ & $\begin{array}{l}\text { "A formação pode ocorrer em etapas, desde } \\
\text { as primeiras experiências, passando pela } \\
\text { formação inicial e continuada e os } \\
\text { primeiros anos de vivência em sala. Assim, } \\
\text { o professor pode se autoformar, interformar } \\
\text { ou heteroformar" (P9). }\end{array}$ \\
\hline & $\begin{array}{l}\text { “Ampliando o leque de espaços de } \\
\text { formação para além da sala de aula, } \\
\text { promovendo situações de aprendizagem } \\
\text { em múltiplos espaços e em múltiplos } \\
\text { níveis, propiciando situações de } \\
\text { aprendizagem que possibilitem pensar a } \\
\text { realidade de uma forma crítica e refletir } \\
\text { sobre a docência como um campo de } \\
\text { luta, de reflexão da prática docente e de } \\
\text { transformação social” (Síntese - P7, P8 } \\
\text { e P9) }\end{array}$ & $\begin{array}{l}\text { "Oportunizando situações de aprendizagem, } \\
\text { em ambientes formais e não formais, que } \\
\text { busquem promover uma formação que } \\
\text { perpasse o entendimento científico, } \\
\text { necessário ao professor, e, vislumbre uma } \\
\text { formação reflexiva que tenha como foco o } \\
\text { entendimento do que se configura formar-se } \\
\text { professor, ser professor de modo } \\
\text { concatenado a uma dimensão ética e } \\
\text { política ao longo dessa formação" (Síntese } \\
\text { - P7, P8 e P9). }\end{array}$ \\
\hline
\end{tabular}

Fonte: As autoras

Na SDI inicial, a participante P7 enaltece a criticidade e a reflexão sobre a docência no processo formativo, pois vê a docência "[...] como um campo de luta e de transformação social", o que foi apresentado também na síntese inicial do grupo 3. Tal concepção encontra acolhida na concepção de docência militante explicitada por Formosinho (2009). Na SDI final, a referida participante defendeu que a formação precisa perpassar o "[...] entendimento 
científico, necessário ao professor". Nesta perspectiva, vislumbramos o conhecimento do conteúdo (GARCIA, 2009) como importante na formação de professores.

Ademais, P7 trouxe a concepção de uma formação reflexiva “[...] que tenha como foco o entendimento do que se configura formar-se professor, ser professor de modo concatenado a uma dimensão ética e política ao longo dessa formação". Aqui notamos a inspiração na obra de Freire estudada na disciplina, pois, para o autor:

A necessária promoção da ingenuidade à criticidade não pode ou não deve ser feita à distância de uma rigorosa formação ética ao lado sempre da estética [...] Estar longe ou, pior, fora da ética, entre nós, mulheres e homens é uma transgressão [...] Se se respeita a natureza do ser humano, o ensino dos conteúdos não pode dar-se alheio à formação moral do educando. Educar é substancialmente formar (2014, p. 34-35).

A participante P8 concebeu as instituições de ensino superior como locais nos quais ocorre a formação inicial e a continuada de modo institucionalizado. Entretanto, reconheceu que a formação pode se dar em outros espaços. Na SDI final ela acrescentou que a "[...] formação de professores é dada no dia a dia do professor, por meio do seu processo de reflexão". A reflexão no processo formativo foi mantida na síntese inicial e final do grupo 3, bem como do grupo 2. Esse resultado aponta que os grupos já iniciaram a disciplina trazendo a concepção que a reflexão é importante na formação de professores. Contudo, verificamos que a reflexão, após a vivência coletiva, trouxe mais elementos que nos permitem inferir a criticidade associada à reflexão, ou seja, a reflexão crítica sobre a prática como elemento indispensável à prática docente. Para Freire (2014, p. 39):

[...] É fundamental que, na prática da formação docente, o aprendiz de educador assuma que o indispensável pensar certo não presente dos deuses nem se acha nos guias de professores que iluminados intelectuais escrevem desde o centro do poder, mas, pelo contrário, o pensar certo que supera o ingênuo tem que ser produzido pelo próprio aprendiz em comunhão com o professor formador $[\ldots]$.

Em relação à citação de Freire (2014) vale esclarecer que pensar certo, para o autor, implica respeito aos estudantes, aceitação do novo e agir eticamente, dentre outras coisas. Para Freire (2014), faz parte da função docente ensinar conteúdos, mas também ensinar a pensar certo, a argumentar com segurança, a criar.

O participante P9 atestou, na SDI inicial, que a formação pode se dar na vivência em sala de aula sem, no entanto, esclarecer como isso se daria. Na SDI final, percebemos que o participante traz que “[...] o professor pode se autoformar, interformar ou heteroformar". Tais 
conceitos, envolvidos no processo formativo, foram trabalhados na disciplina através do livro de Garcia intitulado Formação de professores: para uma mudança educativa. Para Garcia (2009), na autoformação o professor define os objetivos, processos, instrumentos e resultados da própria formação. Já a heteroformação é "uma formação que se organiza e desenvolve 'a partir de fora', por especialistas" (Idem, p. 29-30). Por fim, a interformação ocorre entre os professores em formação inicial ou entre professores em continuada.

No quadro 4 explicitamos as respostas individuais e as sínteses obtidas na SDI inicial e final com os participantes do grupo 4. No mesmo é possível perceber que a pesquisa-ação foi citada por P10 e P12, na SDI inicial, como elemento importante na formação de professores e essa concepção permaneceu na síntese inicial do grupo 4. Thiollent e Colette (2014), ao discutirem os rumos e os princípios da metodologia da pesquisa-ação no contexto da educação e da formação de professores, considerando ações pedagógicas emancipatórias vinculadas a universidades e à educação de modo amplo, atestam que:

$\mathrm{Na}$ abordagem de pesquisa-ação, o docente desempenha um papel de pesquisador sobre: o conteúdo do ensino; o grupo; a didática; a comunicação; a melhoria da aprendizagem dos estudantes; os valores da educação; e o ambiente em que esta ocorre. O professor-pesquisador tem autonomia. Seu ensino está embasado em pesquisa e não em conhecimentos prontos, codificados em material de instrução (THIOLLENT; COLETTE, 2014, p. 213).

Quadro 4- SDI inicial e final em relação à pergunta "Como formar professores?"

\begin{tabular}{|c|c|c|}
\hline \multirow[t]{4}{*}{ Grupo 4} & $\begin{array}{l}\text { Respostas individuais e síntese na SDI } \\
\text { inicial }\end{array}$ & $\begin{array}{l}\text { Respostas individuais e síntese na SDI } \\
\text { final }\end{array}$ \\
\hline & $\begin{array}{l}\text { "Com pesquisas, interações em grupos, } \\
\text { no laboratório que é a escola, sua sala de } \\
\text { aula, aproximando-se das mais diversas } \\
\text { realidades. Com pesquisa-ação" (P10). }\end{array}$ & $\begin{array}{l}\text { "Na mobilização de cada docente, no } \\
\text { interesse, nos estudos contínuos, no } \\
\text { laboratório das salas de aula e nas } \\
\text { inúmeras heterogeneidades. Com } \\
\text { momentos de troca de experiências } \\
\text { constantes/periódicas entre os } \\
\text { professores/educadores de determinadas } \\
\text { escolas e de toda uma rede educacional" } \\
\text { (P10). }\end{array}$ \\
\hline & $\begin{array}{l}\text { "A formação docente principia } \\
\text { formalmente na graduação, caminha no } \\
\text { decorrer do exercício da docência, em } \\
\text { um constante aprender-ensinar. Os } \\
\text { saberes possuem endereços longínquos } \\
\text { que perpassam a trajetória estudantil, as } \\
\text { experiências da vida em seus diversos } \\
\text { contextos, mas a materialidade da } \\
\text { formação ocorre na sala de aula, seja } \\
\text { como aluno ou como professor" (P11). }\end{array}$ & $\begin{array}{l}\text { "A formação principia no processo de } \\
\text { escolarização, se materializa na } \\
\text { formação inicial e continua no exercício } \\
\text { da docência. Então envolve } \\
\text { aprendizagens escolares, a vivência } \\
\text { acadêmica, as experiências e valores } \\
\text { constituídos na caminhada da vida e a } \\
\text { prática da docência" (P11). }\end{array}$ \\
\hline & "Penso que possa ser a partir da análise & "A partir de oportunidades reflexivas \\
\hline
\end{tabular}




\begin{tabular}{|l|l|l|}
\hline $\begin{array}{l}\text { de situações, já pré-estabelecidas, } \\
\text { criando e oportunizando a sala de aula } \\
\text { como um espaço de pesquisa-ação" } \\
\text { (P12). }\end{array}$ & $\begin{array}{l}\text { sobre a prática docente e suas possíveis } \\
\text { metodologias. Deve haver também um } \\
\text { momento em que sejam privilegiadas } \\
\text { ações de humanização, troca de } \\
\text { experiências e ressignificá-las" (P12). }\end{array}$ \\
$\begin{array}{ll}\text { "É preciso que se trabalhe com a "O processo de formação do professor } \\
\text { realidade cotidiana das escolas, para que } \\
\text { os professores não conheçam apenas na } \\
\text { teoria, mas vivenciem na prática o o } \\
\text { processo educativo" (P13). }\end{array}$ & $\begin{array}{l}\text { deve dar nas inter-relações entre a } \\
\text { teoria a prática, onde o professor } \\
\text { utiliza-se do estágio docente como } \\
\text { laboratório para aplicar e experienciar na } \\
\text { prática os saberes adquiridos no decorrer } \\
\text { do curso superior. Além disso, a }\end{array}$ \\
formação é um processo contínuo e \\
permanente em que o professor aprende \\
na troca com o aluno" (P13).
\end{tabular}

Fonte: As autoras

As interações em grupo foram sugeridas pela participante P10 e se mantiveram na síntese inicial do grupo 4, além de serem citadas por P12 na SDI final com o termos "troca de experiências". Tais interações podem ser interpretadas como a interformação (GARCIA, 2009) e que constaram na concepção do participante P9, do grupo 3, na SDI final. Todavia, P10 citou as interações, nas SDI inicial e final, sem se apropriar do termo adequado no campo da formação de professores.

A participante P11 nos disse que "[...] a materialidade da formação ocorre na sala de aula, seja como aluno ou como professor", sinalizando que a formação do professor inicia desde o momento em que ele é estudante, pois ali ele já começa a construir ideias em relação ao que é ser um bom professor ou não. Contudo, Imbérnon (2006) nos lembra que, embora o professor seja influenciado pelo que vivenciou como estudante, ele pode criar e recriar sua prática docente e o que é como pessoa.

A unidade teoria-prática foi outro elemento apontado como importante na formação de professores. Tal unidade foi citada pela participante P13 na SDI inicial e na final, e constou na 
síntese final do grupo 4. Para o grupo 4: "A formação inicia no próprio processo de escolarização, se materializa na formação inicial a partir da inter-relação entre a teoria e a prática, onde o licenciando utiliza o estágio como laboratório para aplicar e experienciar na prática os saberes adquiridos na academia” (síntese final - P10, P11, P12 e P13). Nesse trecho percebemos a inspiração em Gatti (2000), autora estudada na disciplina, para quem muitas deficiências apontadas na literatura quanto à formação dos professores se devem à ausência da concepção de unidade nas relações teoria-prática. Na visão da autora, qualquer teoria se origina na prática social humana, em que estão sempre explícitos pressupostos teóricos.

Em relação ao quadro 4 cabe-nos ainda destacar a concepção de P12 na SDI final, ao afirmar que a formação de professores deve dar-se "A partir de oportunidades reflexivas sobre a prática docente e suas possíveis metodologias". Aqui notamos, mais uma vez, a reflexão sendo apontada como componente relevante na formação de professores, pois a mesma também foi citada pelos grupos 2 e 3 .

Arrematando a análise do quadro 4 inferimos que a síntese do grupo 4 na SDI final traz a finalidade última da formação de professores: “[...] oportunizar à sociedade pessoas melhores (moralmente e intelectualmente).” (Síntese - P10, P11, P12 e P13). A educação, comprometida com a realidade social, constitui prática que requer um conjunto de ações intencionais em prol da sociedade; e uma de suas finalidades é contribuir para a humanização, aspecto destacado por P12 como significativo na formação de professores.

A humanização, como diz Araújo (2015), constitui categoria fundante da pedagogia freireana. A leitura das obras de Paulo Freire permite-nos compreender que o ser humano é ontologicamente vocacionado para ser mais. Logo, a desumanização seria a distorção dessa vocação: "Nem uma nem outra (humanização ou desumanização) são destinos certos, dado dado, sina ou fato. Por isso mesmo é que uma é vocação e outra, distorção da vocação" (FREIRE, 1996, p. 99).

Ainda como parte da SDI, e finalizando a mesma, cada grupo elegeu um representante na SDI inicial e na final, ou seja, após a construção das sínteses por grupos. A função dos representantes era sintetizar as respostas de todos os grupos. Apresentamos, a seguir, a síntese geral dos grupos 1, 2, 3 e 4 sobre como formar professores.

Ampliando o leque de espaços de formação para além da sala de aula, promovendo situações de aprendizagem em múltiplos espaços e em múltiplos níveis, propiciando situações de aprendizagem que possibilitem pensar a realidade de uma forma crítica e refletir sobre a docência como um campo de luta, de reflexão da prática docente e de transformação social. Sendo assim, a formação de professores cria oportunidades de acesso aos 
processos de ensino e aprendizagem, contextualizados com as expectativas através de situações já pré-estabelecidas (Síntese geral de todos os grupos na SDI inicial).

Neste aspecto houve pouco consenso. Ideias chave do consenso: formação inicial e continuada, mobilização para questões sociais, éticas e políticas para uma sensibilização crítica e reflexiva (Síntese geral de todos os grupos na SDI final).

Na SDI inicial os grupos sinalizaram que a formação de professores deve ocorrer em múltiplos espaços, trazendo possibilidades de " [...] pensar a realidade de uma forma crítica e refletir sobre a docência como campo de luta, de reflexão da prática docente e de transformação social”. Desse modo, a concepção militante explicitada por Formosinho (2009) está presente na concepção geral do grupo.

Manteve-se presente no grupo a concepção de formação de professores com viés crítico e reflexivo. Esse resultado sinaliza para a importância de profissionais que tenham um olhar diferenciado para a docência e para a sociedade. É uma postura política que revela a função social da docência: transformar a sociedade. Nesse contexto de valorização do docente como um prático reflexivo, Diniz-Pereira (2002, p. 26), diz que: “os professores têm sido vistos como um profissional que reflete, questiona e constantemente examina sua prática pedagógica cotidiana, a qual por sua vez não está limitada ao chão da escola”.

$\mathrm{Na}$ SDI final, o grupo registrou que não houve consenso em relação a como formar professores. Desse modo, o grupo optou por registrar apenas ideias chave que todos concordaram. Esse fato desvela que, após estudar vários textos de diferentes autores que pesquisam sobre a formação de professores, o grupo percebeu que não há uma "receita" sobre como formar esses profissionais. Mas o grupo apontou que nela deve estar presente “[...] mobilização para questões sociais, éticas e políticas para uma sensibilização crítica e reflexiva".

Essa mobilização nos faz concordar com Nóvoa (1995, p. 26), para quem é necessária a construção de uma nova cultura da formação de professores. Todavia, esse autor adverte que: "Não se trata de mobilizar a experiência apenas numa dimensão pedagógica, mas também num quadro conceptual de produção de saberes”. A troca de experiências docentes, exitosas ou não, representa, por exemplo, a possibilidade de momentos e espaços de formação mútua através da partilha de saberes. Nesse sentido, a formação pode ser compreendida como processo em que há o diálogo entre profissionais empenhados em melhorar a sua própria prática docente e a de outros professores. 


\section{Considerações Finais}

Ao buscarmos concepções de pós-graduandos em educação sobre como formar professores, encontramos que é imprescindível formar para a vida na formação inicial e continuada, valorizando o contexto acadêmico e social. Percebemos que a formação inicial é apenas o início do processo formativo do professor, assim, embora seja o chão dessa formação, necessita continuidade, e uma das possibilidades para continuar é compartilhar experiências através de redes de auto formação participada.

A pesquisa-ação, a necessidade de se conhecer metodologias diversas, de refletir sobre a docência, a unidade teoria-prática, a criticidade e a humanização são também aspectos relevantes a serem considerados no processo formativo. Nesse caso, não basta formar professores que conheçam muito bem os conteúdos específicos a serem lecionados, nem tampouco dominar aspectos metodológicos sobre como ensiná-los; é preciso trabalhar com os futuros professores a importância dos mesmos inserirem-se no contexto de seus estudantes, de lerem o mundo para pronunciá-lo, de lutarem pela transformação da sociedade.

Assim, apontamos que os cursos de formação de professores precisam investir na sólida construção de um projeto pedagógico que possa viabilizar uma formação capaz de contemplar as dimensões científica, cultural, humana, política, ética e estética. E, nesse sentido, há documentos oficiais e pesquisas na área de formação de professores que apontam possíveis caminhos para tal formação: trazer a dimensão ambiental e a questão dos direitos humanos na formação; investir na parceria universidade-escola para que os professores atuantes nas mesmas sejam, verdadeiramente, co-formadores; incentivar a autonomia e a valorização dos saberes dos professores.

O problema é que muitas vezes verificamos que as reformas e proposições na formação de professores e na educação, de modo mais amplo, no Brasil, não valorizam a participação dos professores, ou seja, os saberes daqueles que exercem a docência são pouco valorizados, gerando a ideia de que os professores são meros consumidores e cumpridores das reformas educacionais. À vista disso, parece-nos que um trabalho coletivo envolvendo as instituições formadoras de professores, dirigentes governamentais e escolas públicas torna-se imperioso para a construção de uma proposta de formação de professores. Afinal, a formação de professores precisa dar-se nas instituições formadoras e nas escolas.

A parceria universidade-escola na formação de professores pode também contribuir para algo primordial: a formação continuada dos professores formadores de professores. 
Muitos dos docentes que atuam na formação de professores não são licenciados e não conhecem a realidade escolar e isso os faz formar profissionais para um contexto ao qual eles próprios desconhecem. Quanto a esse assunto vale salientar que a tarefa de formar professores não cabe apenas aos professores das disciplinas pedagógicas, tais como Didática, Metodologia do Ensino e Estágios Supervisionados. Tal tarefa é de todos os professores que atuam no curso de formação de professores.

Por fim, registramos que houve mudança significativa nas concepções apresentadas na SDI inicial e na final. Pelos resultados expostos, os estudantes da pós-graduação em educação apresentaram termos próprios ao campo da formação de professores e interiorizaram autores e ideias atuais da área. Dessa forma, sugerimos que os programas de pós-graduação em educação e em ensino ofertem disciplinas que tenham por foco discutir a formação de professores, tendo em vista que muitos desses pós-graduandos serão professores da educação superior e, consequentemente, possíveis formadores de professores.

\section{REFERÊNCIAS}

ARAÚJO, Monica Lopes Folena. A educação ambiental crítico-humanizadora na formação de professores de biologia. Recife: Editora da UFPE, 2015.

BRASIL. Ministério da Educação. Diretrizes Curriculares Nacionais para a Formação Inicial e Continuada em Nível Superior de Profissionais do Magistério para a Educação Básica. Disponível em: http://pronacampo.mec.gov.br/images/pdf/res_cne_cp_02_03072015.pdf. Acesso em 27 nov. 2017.

BRASIL. Coordenação de Aperfeiçoamento de Pessoal de Nível Superior - CAPES. Portaria $\mathrm{n}^{\circ}$ 46, de 11 de abril de 2016. Aprova o Regulamento do Programa Institucional de Bolsa de Iniciação à Docência - PIBID. Disponível em: https://www.capes.gov.br/images/stories/download/legislacao/15042016-Portaria-46Regulamento-PIBID-completa.pdf. Acesso em 1 dez. 2017.

CANÁRIO, Rui. A prática profissional na formação de professores. In: CAMPOS, Bártolo Paiva (Org.). Formação profissional de professores no ensino superior. Porto, Portugal: INAFOP/Porto Editora, 2000, p. 31-46.

CAPRA, Fritjof. A teia da vida: Uma nova compreensão científica dos sistemas vivos. São Paulo: Cultrix, 2006.

CHARLOT, Bernard. Da relação com o saber às práticas educativas. São Paulo: Cortez, 2013.

CHARLOT, Bernard. Da relação com o saber: elementos para uma teoria. Porto Alegre: Artmed, 2000. 
DINIZ-PEREIRA, Júlio Emílio. A pesquisa dos educadores como estratégia para construção de modelos críticos de formação docente. In: DINIZ-PEREIRA, Júlio Emílio; Zeichner, Kenneth M. A pesquisa na formação e no trabalho docente. Belo Horizonte: Autêntica, 2002. p. 11-42.

FORMOSINHO, João; FERREIRA, Fernando Ilídio. Concepções de professor: diversificação, avaliação e carreira docente. In: FORMOSINHO, João (Org.). Formação de professores: aprendizagem profissional e acção docente. Porto, Portugal: Porto Editora, 2009, p. $19-36$.

FREIRE, Paulo. Extensão ou comunicação? Comunicação? 17. ed. São Paulo: Paz e Terra, 2015.

FREIRE, Paulo. Pedagogia da autonomia: saberes necessários à prática educativa. 49. ed. São Paulo: Paz e Terra, 2014.

FREIRE, Paulo. Pedagogia da esperança. São Paulo: Paz e Terra, 1996.

GARCIA, Carlos Marcelo. Formação de professores: para uma mudança educativa. Porto, Portugal: Porto, 1999.

GATTI, Bernadete. Formação de professores no Brasil: características e problemas.

Educação e Sociedade, Campinas, v. 31, n. 113, p. 1355-1379, out.-dez. 2010. Disponível em: http://www.redalyc.org/html/873/87315816016/. Acesso em 1 dez. 2017.

GATTI, Bernadete. A formação inicial de professores para a Educação Básica: as licenciaturas. Revista USP, São Paulo, n. 100, p. 33-46, dez. jan. fev. 2013-2014. Disponível em: https://www.revistas.usp.br/revusp/article/view/76164. Acesso em 26 nov. 2017.

IMBERNÓN, Francisco. Formação docente e profissional: formar-se para a mudança. 6. ed. São Paulo: Cortez, 2006.

MORAES, Maria Cândida. Pensamento eco-sistêmico: educação, aprendizagem e cidadania no século XXI. Petrópolis, RJ: Vozes, 2004.

MORAES, Maria Cândida; TORRES, Saturnino de la. Sentipensar: fundamentos e estratégias para reencantar a educação. Petrópolis, RJ: Vozes, 2004.

NÓVOA, António. Relação escola-sociedade: novas respostas para um velho problema. In: SERBINO, Raquel Volpato; et al. (Orgs). Formação de professores. São Paulo: Fundação Editora da UNESP, 1998, p. 19-39.

NÓVOA, António. Os professores e sua formação. Lisboa, Portugal: Dom Quixote, 1995.

NÓVOA, António. Profissão professor. Porto, Portugal: Porto, 1991.

OLIVEIRA, Maria Marly de. Sequência didática interativa no processo de formação de professores. Petrópolis (RJ): Vozes, 2013. 
ROMANOWSKI, Joana Paulin. Formação inicial de professores: implicações com a educação básica. In: REBOLO, Flavinês; TEIXEIRA, Leny Rodrigues Martins; PERRELI, Maria Aparecida de Souza (Orgs). Docência em questão: discutindo trabalho e formação. São Paulo: Mercado das Letras, 2012, p. 181 - 203.

SANTANA, Débora Bezerra de; ARAÚJO, Monica Lopes Folena; SANTOS, Silvia Bezerra dos. Estratégias didáticas de escolas de Pernambuco ao participar da Olimpíada de Saúde e Meio Ambiente. Revista Didática Sistêmica, v. 13, n. 2, p. 72- 93, 2011. Disponível em: https://www.seer.furg.br/redsis/article/view/2295/1283. Acesso em 4 dez. 2017.

TARDIF, Maurice. Princípios para guiar a aplicação dos programas de formação inicial para o ensino. In: EGGERT, E. et al. Trajetórias e processos de ensinar e aprender: didática e formação de professores (textos selecionados do XIV ENDIPE). Porto Alegre: EDIPUCRS, 2008, p. 17-46.

THIOLLENT, Michel Jean Marie; COLETTE, Maria Madalena. Pesquisa-ação, formação de professores e diversidade. Acta Scientiarum. Human and Social Sciences. Maringá, v. 36, n. 2, p. 207-216, Jul.-Dec., 2014. Disponível em: http://periodicos.uem.br/ojs/index.php/ActaSciHumanSocSci/article/view/23626/pdf_34. Acesso em 5 dez. 2017.

\section{$\underline{\text { SOBRE AS AUTORAS }}$}

\section{Monica Lopes Folena Araújo}

Doutora em Educação pela Universidade Federal de Pernambuco (UFPE), Departamento de Educação da Universidade Federal Rural de Pernambuco (UFRPE), Programa de PósGraduação em Ensino das Ciências/UFRPE, Grupo de Pesquisa em Formação e Prática Pedagógica de Professores de Ciências e Biologia (CNPq/UFRPE). E-mail: monica.folena@gmail.com

\section{Maria Inêz Oliveira Araújo}

Doutora em Educação pela Universidade de São Paulo (USP), Professora do Departamento de Educação da Universidade Federal de Sergipe (UFS), Programa de Pós-Graduação em Educação/UFS, Grupo de Estudos e Pesquisa em Educação Ambiental de Sergipe (CNPq/UFS). E-mail: inez@ufs.br 